\title{
HANSENÍASE: FORMAS CLÍNICAS E DIAGNÓSTICO DIFERENCIAL
}

\author{
LEPROSY: CLINICAL FORMS AND DIFFERENTIAL DIAGNOSIS
}

Cacilda Silva Souza

Professora Assistente pela Fundação de Apoio ao Ensino, Pesquisa e Assistência do Hospital das Clínicas, da Divisão de Dermatologia do Departamento de Clínica Médica da Faculdade de Medicina de Ribeirão Preto da Universidade de São Paulo.

CorRESPONDÊNCIA: Divisão de Dermatologia - Departamento de Clínica Médica da Faculdade de Medicina de Ribeirão Preto - Campus Universitário - CEP: 14048-900 - Ribeirão Preto - SP. E-mail: cacilda@usp.br

SOUZA, CS. Hanseníase: formas clínicas e diagnóstico diferencial. Medicina, Ribeirão Preto, 30: 325-334, jul./set. 1997.

RESUMO: Este artigo se propõe a realizar uma abordagem centrada nos diversos aspectos clínicodermatológicos da hanseníase, destacando as variações de suas formas clínicas e de seus diagnósticos diferenciais.

UNITERMOS: Hanseníase. Diagnóstico Diferencial.

\section{INTRODUÇÃO}

Hanseníase é doença crônica, granulomatosa, causada pelo Mycobacterium leprae, afetando pele, sistema nervoso periférico e, ocasionalmente, outros órgãos e sistemas. Vários estudos têm demonstrado que, diante da contaminação, a maioria dos indivíduos oferece resistência ao $M$. leprae, não desenvolvendo a doença, situação que pode ser alterada, em função da relação entre agente, meio ambiente e hospedeiro ${ }^{1,2}$.

Nos indivíduos que adoecem, a infecção evolui de maneiras diversas, de acordo com a resposta imunológica, específica, do hospedeiro, frente ao bacilo. Esta resposta imune constitui um espectro, que expressa as diferentes formas clínicas da doença. Com uma resposta imunológica competente, o indivíduo evolui para a forma clínica localizada e não-contagiosa da doença; se esta competência não é efetiva, uma forma difusa e contagiosa é desenvolvida. Entre estes dois extremos, encontram-se as formas intermediárias, que refletem, também, graduais variações da resistência ao bacilo (vide capítulo V).

A principal via de eliminação dos bacilos é a via aérea superior, de doentes das formas multibacilares ou formas abertas da doença.

Subsistem algumas dúvidas com relação à entrada do bacilo no organismo humano. As vias aéreas superiores são, ainda, consideradas como a principal porta de entrada do bacilo; provavelmente, ocorre a infecção transplacentária, e, ainda não totalmente elucidada, e por vezes contestada, a contaminação através do contato cutâneo, de lesões hansênicas, com a pele íntegra de indivíduos normais, ou particularmente aquela com alterações das barreiras de defesa cutânea ${ }^{3}$.

O diagnóstico da hanseníase é baseado em alguns sinais cardinais, como a presença de anestesia em lesões cutâneas, sugestivas da doença, o espessamento de nervos periféricos, e a demonstração do M. leprae no esfregaço de linfa ou cortes histológicos de tecidos.

Para o diagnóstico correto, é necessário o entendimento do conceito espectral da hanseníase, o que possibilita a relação entre o curso clínicoevolutivo e a extensão do comprometimento cutaneoneural, característicos de cada forma clínica da doença. A partir deste conhecimento, são aplicadas classificações, que auxiliam a compreensão, e norteiam a terapêutica. 


\section{CLASSIFICAÇÃO}

A classificação de Madri (1953) adota critérios de polaridade, baseados nas características clínicas da doença, que foram acrescidos pelos aspectos bacteriológicos, imunológicos e histológicos da hanseníase, definindo os grupos polares, tuberculóide (T) e virchoviano (V) ou lepromatoso (L); o grupo transitório e inicial da doença, a forma indeterminada (I); e o instável e intermediário, a forma borderline (B) ou dimorfa (D). Os quatro grandes critérios que definem a classificação da doença são os abaixo citados ${ }^{4}$ :

Clínico: aspectos das lesões cutâneas, variando em número, extensão, definição de margens e simetria de distribuição.

Bacteriológico: presença ou ausência do M. leprae, e seus aspectos morfológicos, variando de numerosos, íntegros e agrupados, formando globias, a raros, fragmentados e ausentes.

Imunológico: imunorreatividade à lepromina - reação de Mitsuda, com leitura após 21 a 28 dias. Atualmente, considera-se positiva a intradermorreação, quando na presença de pápula $\geq$ a $5 \mathrm{~mm}$ de diâmetro ${ }^{5}$.

Histológico: aspectos histopatológicos das lesões, variando de granulomas bem definidos a infiltrado difuso linfo-histiocitário.
As formas clínicas da hanseníase, na classificação de Madri (1953), considerando-se aspectos bacteriológicos e resposta à intradermorreação de Mitsuda, foram relacionadas na Tabela I.

A classificação de Ridley \& Jopling (1966) adota subgrupos dentro do espectro, que obedece, critérios clínicos e bacteriológicos, e enfatiza os aspectos imunológicos e histopatológicos. Siglas são utilizadas para indicar as duas formas polares tuberculóide-tuberculóide (TT) e lepromatoso-lepromatoso (LL) e os três subgrupos: borderline-tuberculóide (BT), borderline-borderline (BB), borderline-lepromatoso (BL).

Em 1982, um Comitê da Organização Mundial de Saúde (OMS) propôs uma classificação simplificada e operacional, indicada para o trabalho de campo, baseada na provável população bacilar, que, por sua vez, relaciona-se às formas clínicas. De acordo com a pesquisa de bacilos no esfregaço de linfa, a baciloscopia, realizada em vários pontos definidos, como lóbulos de orelhas, cotovelos, joelhos e lesões, associada aos critérios clínicos da classificação de Madri (1953), podemos agrupar os pacientes em paucibacilares e multibacilares, e indicar dois diferentes tipos de tratamento ${ }^{5,6}$.

As classificações adotadas para as formas clínicas da hanseníase, a de Madri, a de Ridley \& Jopling

Tabela I - Formas clínicas da hanseníase relacionadas com baciloscopia e reação de Mitsuda, segundo a classificação de Madri

\begin{tabular}{llccc} 
& $\begin{array}{c}\text { Indeterminada } \\
\text { ( I ) }\end{array}$ & $\begin{array}{c}\text { Tuberculóide } \\
\text { ( T ) }\end{array}$ & $\begin{array}{c}\text { Borderline } \\
\text { ( B ) }\end{array}$ & $\begin{array}{c}\text { Virchoviana } \\
\text { ( V ) }\end{array}$ \\
\hline Reação de Mitsuda* & positiva ou negativa & fortemente positiva & negativa a positiva fraca & negativa \\
Baciloscopia & negativa & negativa & positiva a raros bacilos & positiva \\
\hline${ }^{*}$ Considerando-se reação positiva $\geq 5 \mathrm{~mm}$ de diâmetro. (Adaptação do Guia de Controle da Hanseníase, 1994$)^{5}$
\end{tabular}

Tabela II - Correlação entre as classificações de Madri (1953), de Ridley \& Jopling (1966) e da OMS (1982) adotadas para a hanseníase

\begin{tabular}{|c|c|c|c|c|}
\hline MADRI & $\begin{array}{l}\text { Indeterminada } \\
\text { (I) }\end{array}$ & $\begin{array}{c}\text { Tuberculóide } \\
\text { (T) }\end{array}$ & $\begin{array}{l}\text { Borderline } \\
\text { (B) }\end{array}$ & $\begin{array}{c}\text { Virchoviana } \\
\text { V }\end{array}$ \\
\hline Ridley \& Jopling & & TT & $\mathrm{BT}^{*} \mathrm{BB} \mathrm{BL}$ & LL \\
\hline OMS & PAU & LARES & \multicolumn{2}{|c|}{ MULTIBACILARES } \\
\hline
\end{tabular}

TT: Tuberculóide-tuberculóide; *BT: Borderline-tuberculóide, embora apresente características da forma paucibacilar, operacionalmente tem sido classificada como multibacilar; BB: Borderline-borderline; Borderline-lepromatoso e LL: Lepromatoso-lepromatoso. 
e a da OMS, podem ser correlacionadas, como mostra a Tabela II.

\section{FORMAS CLÍNICAS DA HANSENÍASE}

\subsection{Hanseníase Indeterminada}

Comumente, a lesão inicial se expressa como uma área de hipoestesia definida ou não por uma lesão visível. A mais comum manifestação cutânea é o surgimento de uma ou algumas máculas de hipopigmentadas a discretamente eritematosas, e mais secas do que a pele circunjacente, medindo em geral poucos centímetros de diâmetro. Segundo Jopling \& Mc Dougall, $1991^{3}$, é um estágio inicial e transitório da hanseníase, que pode ser encontrado em indivíduos de resposta imune não definida diante do bacilo, usualmente, crianças.

A hanseníase indeterminada pode evoluir com cura espontânea, desenvolver-se lentamente, ou, ainda, involuir, ressurgindo, tardiamente, com características clínicas definidas, dentro do espectro da doença, de acordo com sua capacidade de resposta imune ao M. leprae ${ }^{7}$.

\subsection{Hanseníase Tuberculóide}

No pólo de resistência, a hanseníase tuberculóide caracteriza a forma clínica de contenção da multiplicação bacilar, dentro do espectro da doença. As lesões cutâneas, com bordas pronunciadas, são únicas ou em pequeno número, e assimetricamente distribuídas pelo tegumento. Apresenta-se, quando má- cula, como lesão hipocrômica ou eritematosa, delimitada por micropápulas, e, quando placa, como lesão eritematosa ou acobreada, difusamente infiltrada, ou com tendência central ao aplainamento, e limites externos sempre nítidos e bem definidos (Figura 1A e 1B). Em geral, as lesões não ultrapassam $10 \mathrm{~cm}$ de diâmetro, e os danos em ramos neurais se acentuam rapidamente, resultando em alterações tanto sensitivas quanto autonômicas, que evoluem para hipoestesia e anestesia, em pele de superfície seca, hipoidrótica, com diminuição ou ausência de pêlos. Além da pele, o envolvimento de troncos nervosos ocorre em pequeno número, usualmente, próximo às lesões cutâneas. Os nervos preferencialmente acometidos são o cubital, mediano, radial, peroneiro comum, tibial posterior, auricular e supraorbitário. Neste grupo clínico, podemos encontrar somente comprometimento neural, sem lesões cutâneas, denominando-se hanseníase tuberculóide neural pura.

$\mathrm{Na}$ forma tuberculóide, ao ser avaliada a resposta imune ao $M$. leprae, através da intradermorreação de Mitsuda, observa-se uma reação fortemente positiva, sempre maior que $5 \mathrm{~mm}$, atingido até 8 a $15 \mathrm{~mm}$ de diâmetro, freqüentemente com ulceração central. A baciloscopia, via de regra, é negativa; em alguns casos, encontram-se raros bacilos na histopatologia de cortes de pele, observando-se infiltração de células epitelióides, gigantócitos circundados por linfócitos, na periferia, constituindo granuloma bem definido, que invade a derme e, por vezes, a epiderme, além de com-
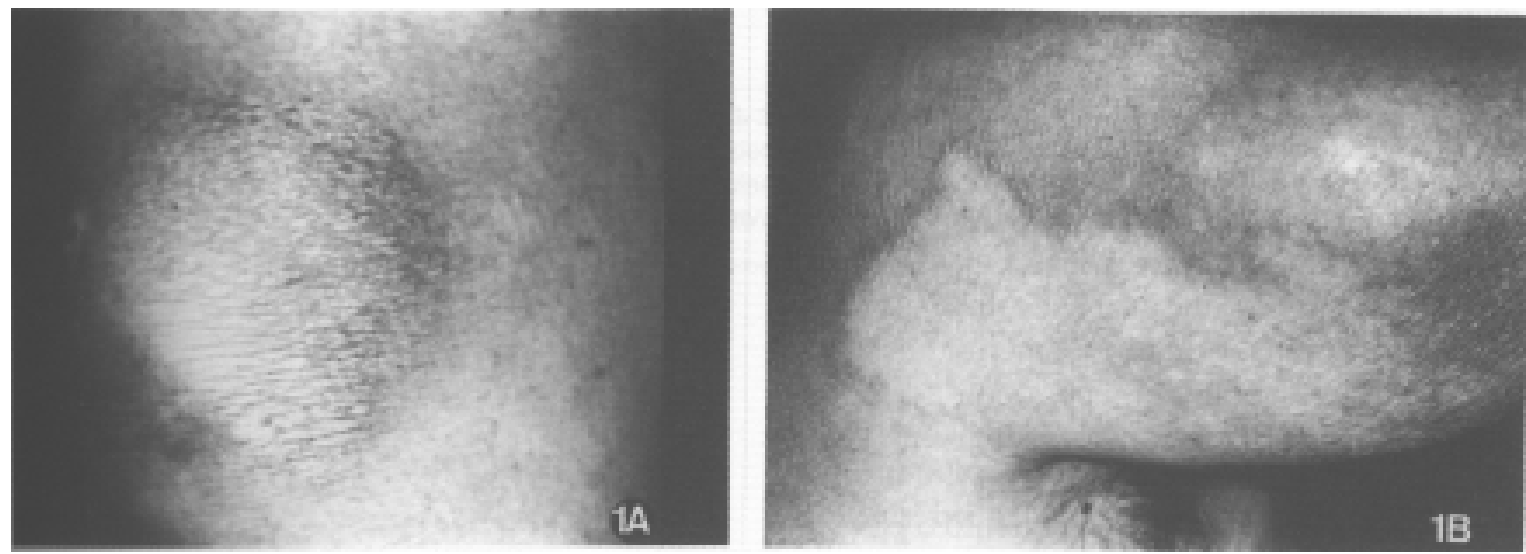

Figura 1- Lesão em placa, eritematoinfiltrada, delimitada por bordas bem definidas, com tendência ao aplainamento central, na região do joelho (1A), e lesão hipocrômica, delimitada por micropápulas, em face lateral do braço, próximo ao cavo axilar (1B), representam características clínicas da hanseníase tuberculóide. 
prometer filetes nervosos, e anexos cutâneos, como glândulas sudoríparas e aparelho pilossebáceo.

\subsection{Hanseníase Virchoviana}

No pólo de anergia, a hanseníase virchoviana expressa a forma clínica de susceptibilidade ao bacilo, resultando em multiplicação e disseminação da doença. De início insidioso e progressão lenta, esta forma clínica avança através dos anos, envolvendo difusamente extensas áreas do tegumento, múltiplos troncos nervosos, e inclusive outros órgãos, até que o paciente perceba seus sintomas. Inicia-se com máculas mal definidas, discretamente hipocrômicas ou eritematosas, pouco visíveis, ampla e simetricamente distribuídas sobre a superfície corpórea. A progressão da doença resulta em acentuação do eritema e infiltração, pele luzidia, com poros dilatados, tipo "casca de laranja", e sobre estas áreas se sobrepõem pápulas, nódulos e tubérculos. Frequentemente comprometidos estão: a região frontal, centromedial da face, e lóbulos da orelha, caracterizando a fácies leonina, além de extensas áreas do tegumento; usualmente, as regiões mais quentes, como axilas, linha média do dorso, períneo e virilhas são poupadas. Nos membros, há comprometimento das superfícies extensoras, particularmente antebraços, dorso das mãos e extremidades, tanto dos membros superiores, como dos inferiores, observando-se articulações e dígitos edemaciados. As lesões encontramse com diminuição ou ausência de pêlos; na face, o comprometimento na cauda da sobrancelha é denominado madarose. Com a evolução da doença, múltiplos troncos nervosos são comprometidos simetricamente, tornam-se, de firmes, a espessados, fibrosos e endurecidos e, progressivamente, sobrevêm a perda sensitiva e a motora, conseqüentemente, levando à perda da função, atrofia muscular, paralisias, deformidades e contraturas. (Figura 2 e 3 ).

$\mathrm{Na}$ forma virchoviana avançada, freqüentemente, o trato respiratório superior está envolvido, ocasionando mucosa congesta e edemaciada, obstrução, coriza mucopurulenta, epistaxe, anosmia, e, finalmente, perfuração septal e desabamento nasal. Pode-se observar tecido friável e com ulcerações em palato, língua, orofaringe e laringe.

O curso da doença se desenvolve, atingindo outros órgãos e sistemas, como olhos, rins, fígado, baço e testículos. Tardias lesões ósseas são conseqüentes, principalmente, a traumas por perda de sensibilidade, osteomielite recorrente, além da osteoporose do desuso, pela paralisia, resultando em lenta atrofia e absorção das falanges, e, em base dos metatarsos, a inadequada distribuição de sobrecarga, torna-se agravante para o surgimento das úlceras plantares.

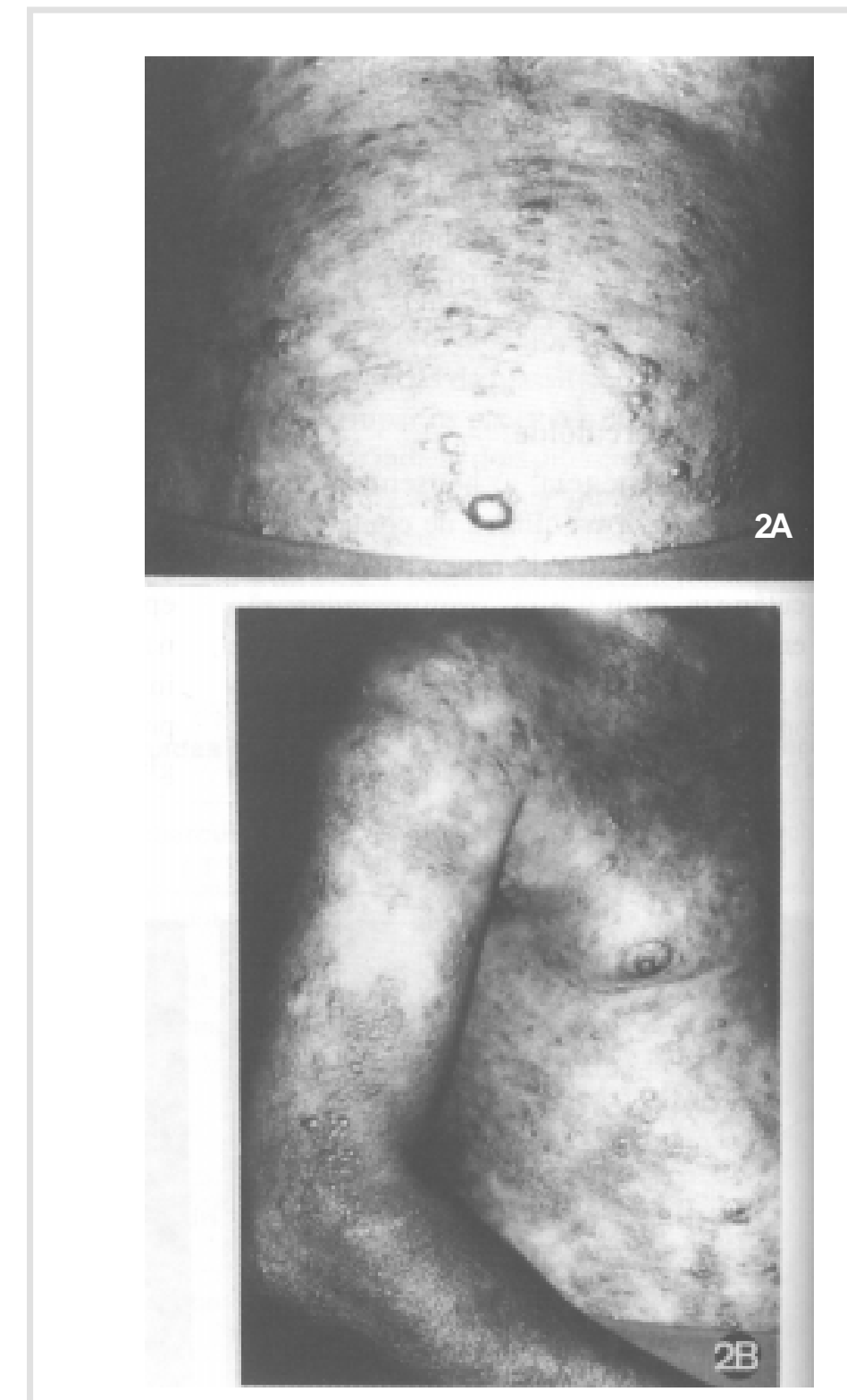

Figura 2 - Pápulas, nódulos e tubérculos, sobre área difusamente eritematosa e infiltrada, sem definição de limites, observadas no abdome (2A), tronco e membro superior (2B) são representativas da hanseníase virchoviana. 
Estima-se a quantidade de $10^{9}$ bacilos/grama de tecido e contínua bacilemia de $10^{5}$ organismos $/ \mathrm{mm}^{3}$ de sangue ${ }^{7}$ esteja presente na hanseníase virchoviana; evidentemente, a baciloscopia é francamente positiva em vários pontos pesquisados. A resposta diante dos antígenos bacilares, a reação de Mitsuda, é negativa, e, na histopatologia da pele, observa-se epiderme atrófica com aplainamento das suas cristas papilares, presença da faixa de Unna, separando a epiderme da zona do infiltrado dérmico. Este infiltrado, monótono e monomórfico, se constitui, sobretudo, de histiócitos, em diversos graus de evolução, que resultam, finalmente, em células espumosas, volumosas, e multivacuoladas, denominadas células de Virchow; observa-se a presença de raros linfócitos e plasmócitos. Além da invasão da derme e tecido subcutâneo, o infiltrado envolve plexo vasculonervoso, glândulas sudoríparas e aparelho pilossebáceo. A pesquisa do bacilo mostra-o íntegro, aglomerando-se em globias, dentro do citoplasma de histiócitos, em filetes nervosos, paredes vasculares, músculo eretor do pêlo, etc.

\subsection{Hanseníase Borderline ou Dimorfa}

Dentro do espectro da doença, esta forma está caracterizada por instabilidade imunológica, e caminha entre os pólos tuberculóide e virchoviano. Devido ao grande contingente de pacientes neste grupo, esta forma clínica, representa destacada parte do espectro, sendo relevantes, também, a freqüência e gravidade dos danos neurais, responsáveis por incapacidades e deformidades na hanseníase.

Na hanseníase borderline ou dimorfa, podemos observar aspectos clinicodermatológicos, que se aproximam do pólo virchoviano ou tuberculóide, até no mesmo paciente, e esta aparência dimorfa reflete a instabilidade imunológica. A evolução da doença e a ausência de tratamento poderiam conduzir alguns pacientes ao pólo virchoviano. Dentro da multiplicidade de aspectos das lesões cutâneas, podemos observar desde máculas, eritematosas, em pele clara, a hipocrômicas, em pele escura, que assume por vezes to-
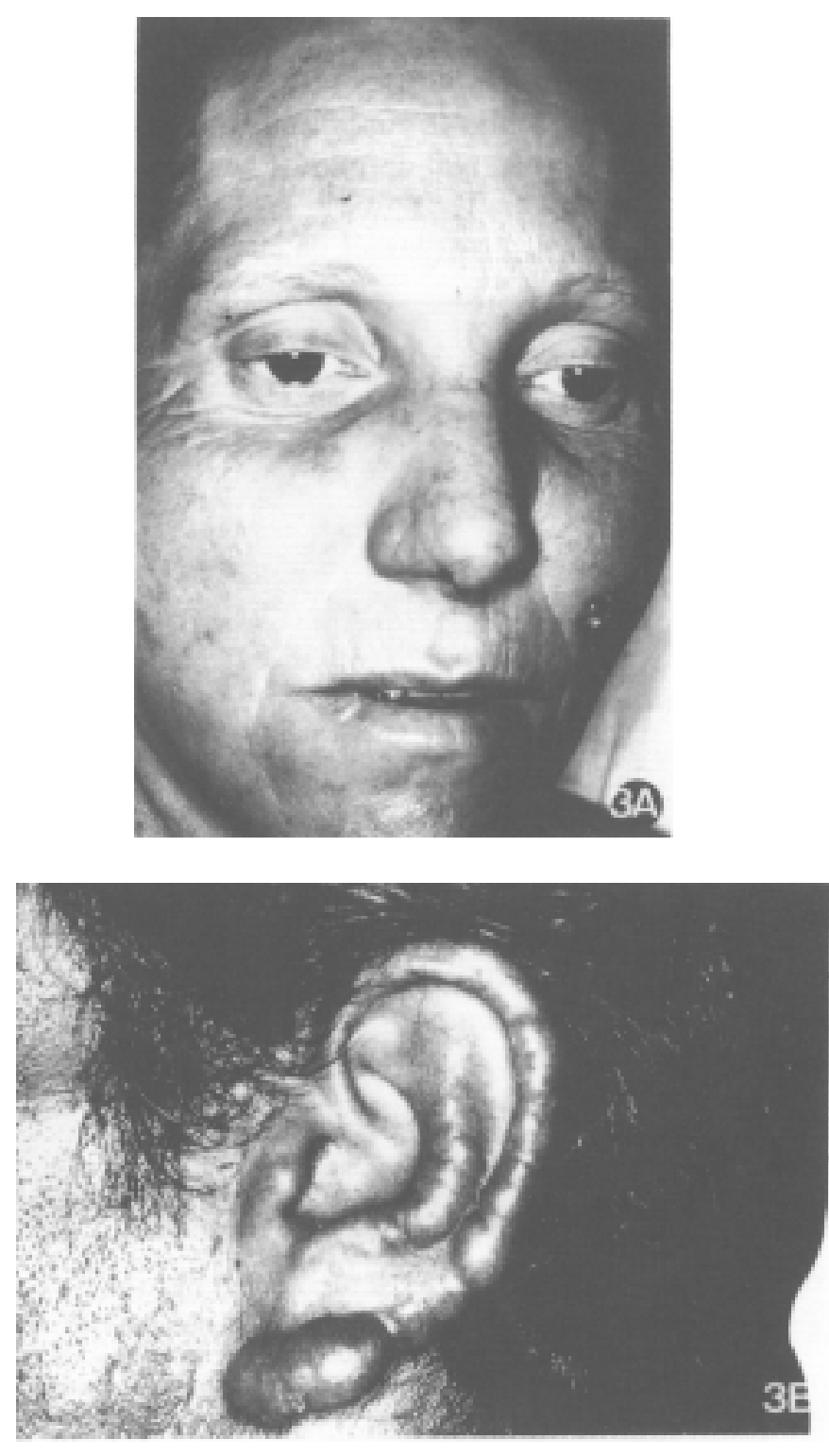

Figura 3 - Eritema e infiltração difusos da face, pele luzidia, com poros dilatados, rarefação da cauda das sobrancelhas e cílios (3A) e pavilhão auricular infiltrado com nódulos (3B) podem ser observados nas fases mais avançadas da Hanseníase virchoviana.

nalidade acobreada, sendo comum também a presença de pápulas, tubérculos, nódulos e placas. À proximidade ao pólo tuberculóide observa-se lesões mais delimitadas, anestésicas e de superfície seca, a pesquisa aponta raridade ou ausência de bacilos. Por outro lado, à proximidade ao pólo virchoviano observase lesões mais numerosas, brilhantes, com menor definição de limites, cuja perda de sensibilidade não é tão intensa, e a pesquisa mostra presença de maior número de bacilos. Foram descritas, classicamente, 
como representantes do grupo borderline, lesões de aspecto anular, circulares e ovais, ou foveolar. Lesões anulares possuem anel eritematoacobreado, mais delimitado interna e externamente, quando comparadas às foveolares, estas últimas denominadas também de lesões tipo queijo-suiço, são representadas por placas eritematosas, cujos limites externos mal definidos, com eritema que se esmaece, gradativamente, contrastam com a definição mais acentuada dos limites internos da borda da lesão cutânea. Pode-se encontrar um grau de anestesia no centro das lesões anelares e foveolares. (Figura 4).

Dentro da classificação de Ridley \& Jopling (1966), as lesões cutâneas, representadas pelo grupo borderline-tuberculóide, assemelham-se às da hanseníase tuberculóide, tendem a ser definidas e hipocrômicas, embora sejam menos marcantes quanto à infiltração e pronunciamento de suas bordas, que, por sua vez, não são bem delimitadas e, gradualmente, se confundem com pele normal. Há variação na defini- ção das margens destas lesões, quando são comparadas em toda a sua extensão e entre si, podem ser mais elevadas e bem definidas, ou aplainadas e vagamente delimitadas. Freqüentemente se observam lesões satélites, próximas às margens de placas extensas. $\mathrm{O}$ número de lesões tende a ser superior a 10 ou 20, e, se as lesões forem comparadas às da hanseníase tuberculóide, têm maiores dimensões, chegando a atingir todo um membro. As lesões neurais são significativas, frequientemente graves, atingindo mais de um tronco nervoso com padrão assimétrico ${ }^{7}$.

A forma clínica borderline - borderline é a mais instável dentro do espectro. Em geral, numerosas lesões cutâneas, que tendem à distribuição simétrica, de diversos tipos e dimensões, estão presentes no mesmo paciente. Máculas, pápulas e placas, de tamanhos variados, podem mostrar desde margens bem definidas, em algumas áreas, até margens pobremente demarcadas, em outras, revelando o aspecto geográfico ou o aspecto polimórfico das lesões ${ }^{7}$.
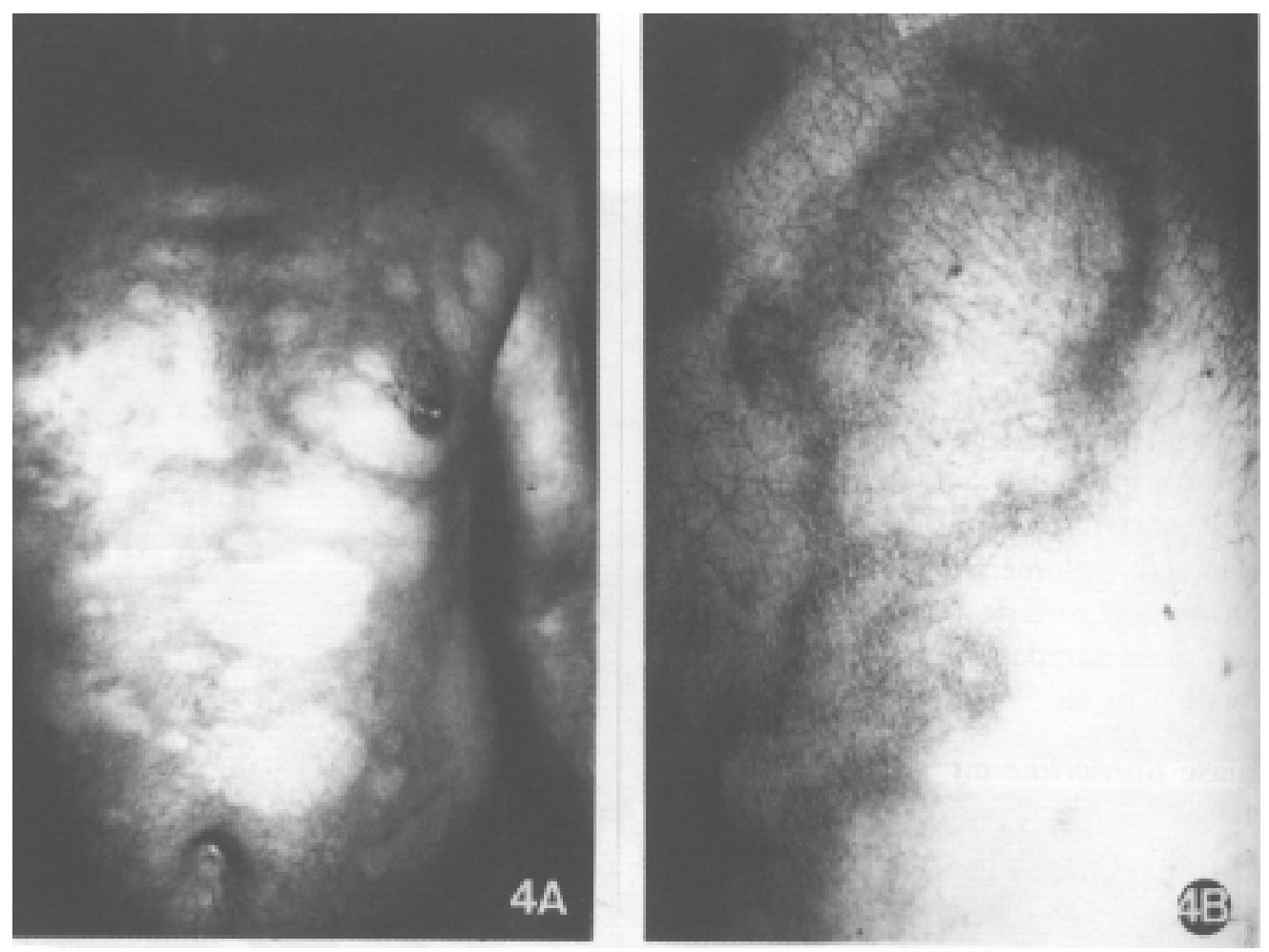

Figura 4 - Lesões anelares e foveolares difusas, em tronco (4A), cujas bordas eritematoinfiltradas apresentam limites internos mais nítidos que os externos (4B), características que se tornam mais acentuadas na proeminência da reação hansênica (tipo 1), a exemplo deste caso clínico de hanseníase dimorfa. 
$\mathrm{Na}$ forma clínica borderline-virchoviana, máculas se disseminam, progressivamente, pelo tegumento, mais distintas e elevadas, quando comparadas ao pólo LL, e posteriormente, estas lesões podem dar lugar a uma infiltração difusa. Pápulas e nódulos coexistem neste quadro, um pouco mais definidos e, que de maneira geral, tendem à distribuição menos simétrica quando comparada ao pólo virchoviano ${ }^{7}$.

A esta variação clínicodermatológica do grupo borderline, estão correlacionados aspectos bacteriológicos, histopatológicos e imunológicos. Podemos observar desde reação intradérmica de Mitsuda positiva, e raridade ou ausência de bacilos, na forma borderline-tuberculóide, até ausência de resposta à reação de Mitsuda, com numerosos bacilos, na pesquisa usual: esfregaço de linfa e cortes histológicos de tecido. (Figura 5).

\subsection{Reações Hansênicas}

Concomitante, ao curso natural da hanseníase, sobrepondo-se a uma evolução usualmente lenta e indolente e, relacionando-se ao espectro clínico, imunológico e histopatológico da doença, impõem-se os estados reacionais, produzidos por diferentes mecanismos imunológicos e responsáveis por importante componente de dano tecidual. As reações hansênicas podem corresponder à exacerbação da imunidade celular, ou demonstrar efeitos de acentuada formação de imunocomplexos, que foram denominadas por Jopling de reação hansênica tipo 1 e tipo 2, respectivamente ${ }^{3}$.

\subsubsection{Reação Reversa}

A reação hansênica tipo 1 , ou reversa, estaria associada à imunidade mediada por célula, classicamente representada pela reação tipo IV de Coombs e Gell, sendo, possivelmente, desencadeada por reação aos antígenos bacilares fragmentados, e súbito aumento da imunidade mediada por células. Comumente, observada em pacientes borderline, após o início da terapêutica, é, em geral, mais precoce nos pacientes BT e $\mathrm{BB}$, do que nos $\mathrm{BL}^{7}$.

$\mathrm{Na}$ reação reversa, as lesões preexistentes tornam-se eritematovioláceas, sensíveis, intumescidas, elevadas, e máculas tornam-se placas. Ocorre, também, elevação e melhor definição dos limites das lesões. Evoluem com descamação e, por vezes, sobrevém ulceração. Novas lesões tendem a surgir, em áreas adjacentes, assemelhando-se às lesões preexistentes, e podem ser numerosas, pequenas e esparsas ( $\mathrm{Fi}$ gura 6A). Nos pacientes BL, edema acrofacial pode estar presente, assim como sintomas sistêmicos, como febre e mal-estar, que não são usuais.

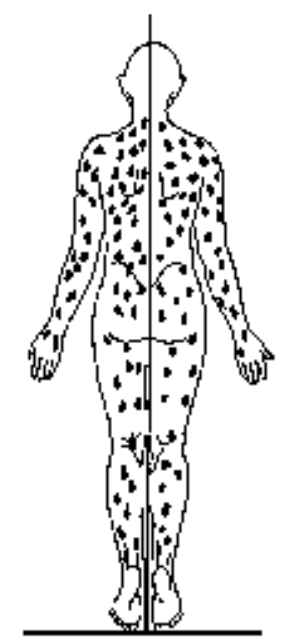

\section{Forma Multibacilar \\ - Infiltração difusa; \\ - Múltiplas lesões, pequenas e brilhantes; \\ - Distribuição simétrica; \\ - Múltiplos nervos comprometi- dos; \\ - Baciloscopia positiva; Reação de Mitsuda negativo}

\section{$5 \mathrm{~A}$}

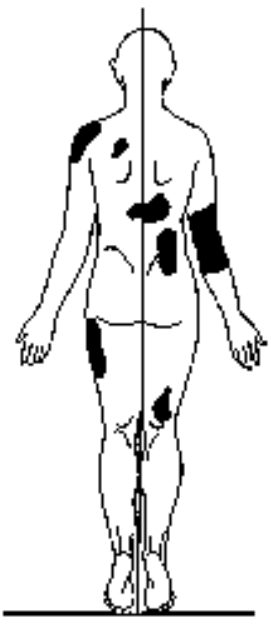

Forma Paucibacilar

- Única ou poucas lesões;

- Tamanhos variáveis, seca e descamativa;

- Distribuição assimétrica;

- Poucos nervos comprometidos;

- Baciloscopia negativa Reação de Mitsuda: (+) T e BT, (+) ou (-) no I

\section{$5 B$}

Figura 5 - Representação esquemática de formas clínicas, multibacilar (5A) e paucibacilar (5B), da hanseníase, quanto ao aspecto e distribuição das lesões, comprometimento dos nervos, baciloscopia e resposta à reação de Mitsuda. T: tuberculóide; BT: borderline-tuberculóide; I: Indeterminada. (Esquema modificado de Hastings, 1985). 


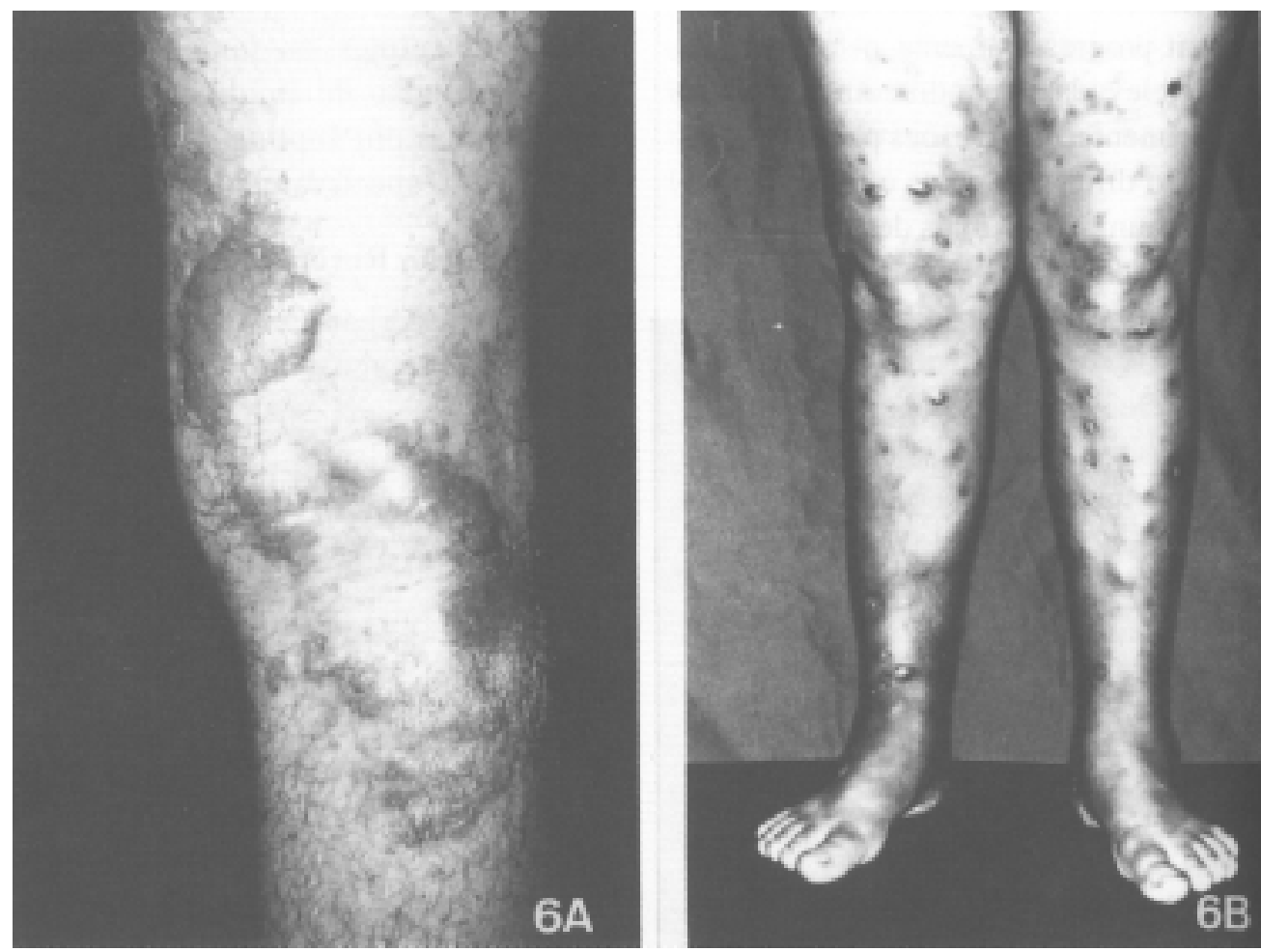

Figura 6 - Na reação reversa ou hansênica, tipo 1 de Jopling, lesões prévias tornam-se eritematoedematosas, além do surgimento de lesões semelhantes em áreas adjacentes (6A); na reação de eritema nodoso hansênico, ou tipo 2 de Jopling, nódulos eritematosos, quentes e dolorosos, surgem em face, membros e tronco (6B).

O comprometimento neural é comum, por vezes, acentuado e grave, resultando, ocasionalmente, em marcante perda de função e paralisia súbita. Nervos comprometidos tornam-se intumescidos, com graus variáveis de dor, e exacerbação da sensibilidade, local e/ou territorial, destacando-se o comprometimento dos sítios de predileção, como nervos ulnar, mediano, radial, peroneiro comum, tibial posterior e supra-orbitário. (Figura 7).

\subsubsection{Reação Tipo Eritema Nodoso}

Por outro lado, a reação hansênica tipo 2, ou tipo eritema nodoso, relaciona-se à deposição de imunocomplexos, semelhante à reação tipo III de Coombs e Gell. Assim, como mecanismos humorais, aqueles mediados por célula, podem estar envolvidos na patogênese da reação tipo eritema nodoso.

As lesões cutâneas da reação hansênica tipo 2, o eritema nodoso hansênico, representam parte das manifestações de um comprometimento multissistêmi- co. A reação tipo 2 ocorre em pacientes multibacilares, e reflete um processo inflamatório agudo, envolvendo qualquer órgão ou tecido em que o bacilo ou seus antígenos estejam presentes. Manifesta-se com queda do estado geral, prostração pela dor, anorexia, febre, insônia e depressão. A face, mãos e pés tornam-se edemaciados, assim como o fígado, baço, e gânglios podem ter seu volume aumentado.

$\mathrm{O}$ freqüente comprometimento de nervos, olhos e testículos, torna importante a reavaliação rotineira destes, nos episódios reacionais, já que a precoce intervenção terapêutica auxilia na prevenção de sequielas tardias.

No episódio de reação tipo eritema nodoso, quando há erupção cutânea, a pele, aparentemente normal, é acometida com surgimento súbito, de pápulas, nódulos e placas, dolorosos e tensos, ao toque, de coloração rósea a eritematoviolácea, com margens não definidas, que evoluem com descamação central, e podem tornar-se hemorrágicas e vesicobolhosas, chegando a se ulcerar (Figura 6B). O surgimento de lesões 
obedece a uma distribuição simétrica, bilateral, mais difusa, quando comparada ao eritema nodoso de outras etiologias, e freqüentemente atinge face, tronco, áreas extensoras de membros, mas poupa couro cabeludo, virilhas e axilas. As lesões hansênicas preexistentes não sofrem alterações. Surgem em surtos, e novas lesões coexistem com antigas, duram cerca de 7 a 10 dias, embora não sejam infreqüentes surtos recorrentes, após semanas, meses ou anos. (Figura 6).

A reação tipo eritema nodoso hansênico, pode ocorrer em pacientes multibacilares, não tratados, embora seja mais freqüente, após o início da terapêutica, e, por vezes, persiste, em alguns pacientes, durante um período posterior ao término do tratamento com poliquimioterapia. Fatores, como infecções intercorrentes, gravidez, vacinação, estresse emocional, alguns fármacos, têm sido associados à precipitação da reação hansênica tipo eritema nodoso ${ }^{3 / 5}$, porém, estão ainda por ser esclarecidos, os mecanismos envolvidos na etiopatogenia desta reação hanseníca, possivelmente, há coexistência de alta carga bacilar e baixa eficácia na eliminação de restos bacilares, entre outros.

\subsubsection{Fenômeno de Lúcio}

Reconhecido como o terceiro tipo de reação hansênica, caracteriza-se por necrose de arteríolas, quando o endotélio é maciçamente invadido por M. leprae $^{8}$. Lúcio \& Alvarado (1852) descreveram reação necrotizante da pele, particularmente na forma clínica difusa e sem nódulos da hanseníase. Posteriormente, esta reação, foi denominada fenômeno de Lúcio, por Latapi et al. $1948^{9}$, que reconheceram alterações histopatológicas de vascularite múltipla, aguda, necrosante, associada à esta forma pura, primitiva e difusa da hanseníase.

No pólo de baixa resistência ao bacilo, no espectro da doença, a hanseníase de Lúcio - Latapi e o fenômeno de Lúcio são comuns no México e América Central, mas infrequientes em outras partes do mundo ${ }^{10}$.

Apesar de descrito quadro clínico e histopatológico do fenômeno de Lúcio, a patogênese desta reação ainda permanece obscura. Claramente, a bacilemia, em células endoteliais, associada a fenômenos trombóticos, é importante; entretanto, prováveis fatores imunológicos, como depósito de complexo imune em vasos da derme, genéticos, regionais, e próprios do M. leprae, considerados como envolvidos na etiopatogenia desta manifestação clínica, necessitam de um substancial investimento de pesquisa.

\section{DIAGNÓSTICO DIFERENCIAL DAS FORMAS CLÍNICAS DA HANSENÍASE}

1. Lesões Maculares - Podemos listar, entre os diagnósticos diferenciais, nevos hipocrômicos e anêmicos, vitiligo, pitiríase versicolor, treponemoses, como sífilis e pinta, hipocromia residual pós-inflamatória, dermatite seborréica e a pitiríase alba.

2. Placas Infiltradas - Constituem diagnóstico diferencial destas lesões a psoríase, dermatite seborréica, pitiríase rósea de Gibert, esclerodermia localizada, líquen plano, líquen mixedematoso, sarcoidose, lúpus eritematoso, tinea corporis, leishmaniose, cromomicose, esporotricose, tuberculose, paracoccidioidomicose e parapsoríase.

3. Lesões anulares - Estão entre os diagnósticos diferenciais a tinea corporis, o granuloma anular, a necrobiose lipoídica, o eritema anular centrífugo e o eritema multiforme.

4. Lesões papulares a nodulares - Neurofibromatose de von Recklinghausen, sarcoma de Kaposi, leishmaniose, sífilis, paracoccidioidomicose, lobomicose, xantomatoses, farmacodermias, e hematodermias.

5. Infitltração difusa disseminada - Leishmaniose difusa anérgica, linfoma cutâneo de células T (micose fungóide), síndrome de Sezary, leucoses com disseminação cutânea e mixedema generalizado, associado ao hipotireoidismo.

6. Neuropatias - Além da hanseníase, o espessamento de nervos periféricos é encontrado em neuropatias, muito pouco freqüentes, como a de Charcot-MarieTooth, a doença de Déjérine-Sottas e a doença de Refsum, que podem ser consideradas no diagnóstico diferencial. As polineuropatias, com alterações sensitivas, motoras, ou ambas, também são incluídas nesta lista. Doenças com perda predominante da função motora incluem a difteria, o botulismo, a mononucleose infecciosa, a brucelose, a porfiria, intoxicação por ouro, além da doença de Déjérine- Sottas. A disfunção predominantemente sensorial pode ocorrer na leucemia, doença de Hodgkin e na isquemia neuropática. A perda mista, motora e sensorial, semelhante à da hanseníase, ocorre na intoxicação por arsênico, brômio, tálio ou mercúrio, por uso de drogas, como isoniazida e talidomida, e nas doenças como o diabetes mellitus, amiloidose, lúpus eritematoso sistêmico e esclerodermia. 


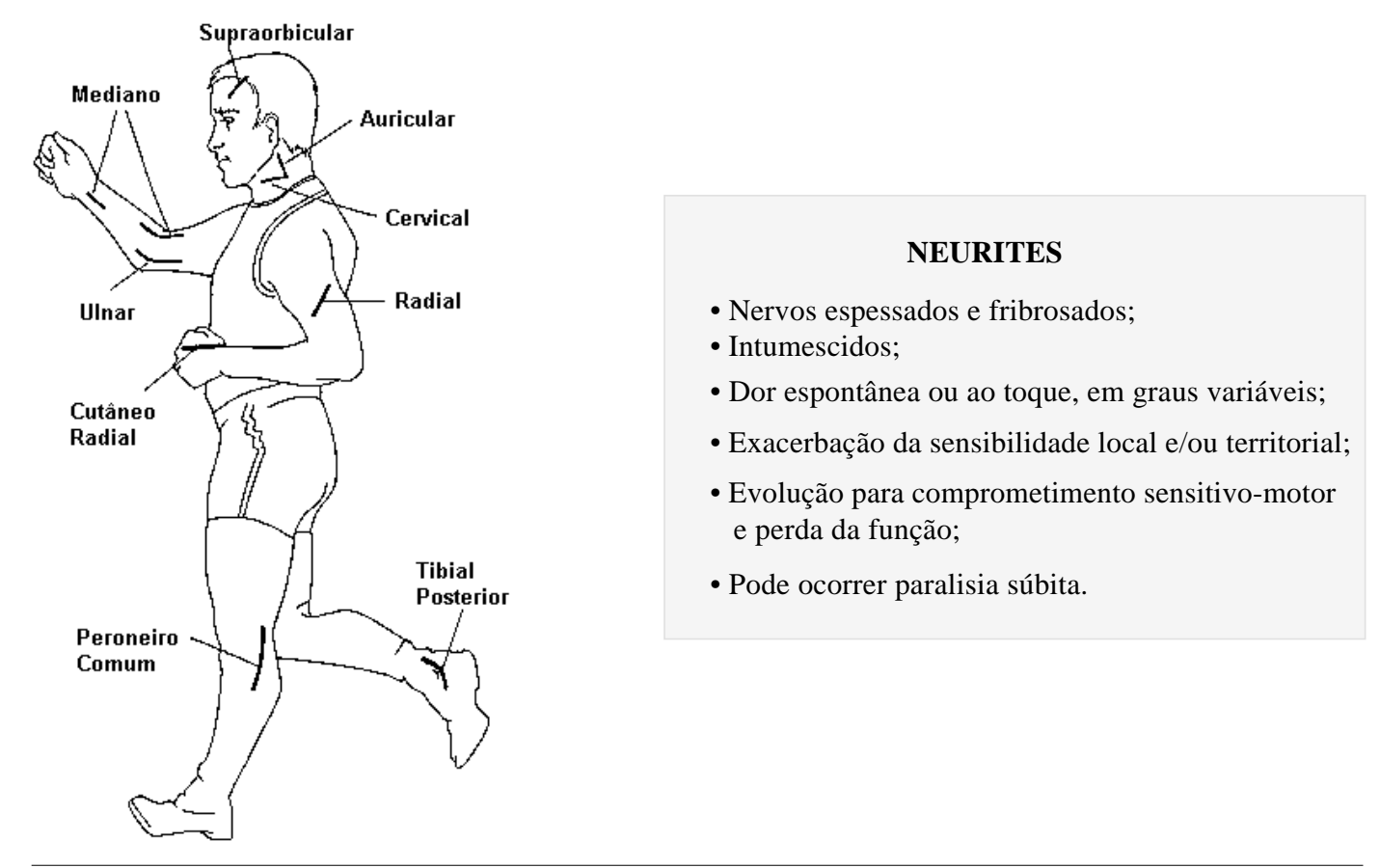

Figura 7 - Esquema representativo da localização de nervos periféricos, que devem ser avaliados ao exame neurológico de rotina e na vigência de neurites; seus principais sinais e sintomas estão listados no quadro ao lado. (Modificado de Hastings, 1985).

SOUZA, CS. Leprosy: clinical forms and differential diagnosis. Medicina, Ribeirão Preto, 30: 325-334, july/sept. 1997.

ABSTRACT: The objective of the present review was to approach the different clinical-dermatologic aspects of leprosy, with emphasis on the variations of the clinical forms and differential diagnosis of the disease.

UNITERMS: Leprosy. Diagnosis, Differential.

\section{REFERÊNCIAS BIBLIOGRÁFICAS}

1 - BECHELLI LM \& CURBAN GV. Infecções microbianas da pele. In: Compêndio de dermatologia, $6^{2} \mathrm{ed}$, Atheneu Editora, São Paulo, p. 131-186, 1988.

2 - LOMBARDI C et al. História natural da hanseníase. In: Hanseníase: epidemiologia e controle, IMESP SASEP, São Paulo, p. 13-20, 1990.

3 - JOPLING WH \& Mc DOUGALL AC. A doença. In: Manual de hanseníase, 4ํe․ Atheneu Editora, São Paulo, p. 11-59, 1991.

4 - LANGUILLON J \& CARAYON A. Lésions cutanées. In: Précis de léprologie, $2^{\circ}$ ed, MASSON, Paris, p. 62-101, 1986.

5 - BRASIL. MINISTÉRIO DA SAÚDE. FUNDAÇÃO NACIONAL DA SAÚDE. Guia de controle da hanseníase. $2^{\circ}$ ed., MS/FNS/CENEPI/CNDS, Brasília, 156 p., 1994.
6 - WORLD HEALTH ORGANIZATION. Chemotherapy of leprosy for control programmes. WHO, Geneva, Technical Report Series, № 675, 1982.

7 - PFALTZGRAFF RE \& BRYCESON A. Clinical leprosy. In: HASTING RC, ed. Leprosy, Churchill Livingstone, New York, p.134-176, 1985.

8 - NAAFS B. Leprosy reactions: New knowledge. Trop Geogr Med 6: 80-84, 1994.

9 - LATAPI F \& ZAMORA AC. The "spotted" Leprosy of Lucio (La lepra "Manchada" de Lúcio): An Introduction to its Clinical and histological study. Int J Lepr 16: 421- 429, 1948.

10 - SAUL A \& NOVALES J. La Lepre de Lucio-Latapi et le phenomene de Lúcio. Acta Lepr 1: 115-132, 1983.

Recebido para publicação em 02/07/97

Aprovado para publicação em 30/07/97 